OPEN ACCESS

Edited by:

Frederic Saltel,

INSERM U1053 Bordeaux Recherche en Oncologie Translationnelle, France

Reviewed by:

Concepción Vicenta Llorente

Instituto de Investigaciones

Biomédicas de Barcelona (IIBB), Spain

Alessandra Ghigo,

University of Turin, Italy

${ }^{*}$ Correspondence:

Jérôme Devy

jerome.devy@univ-reims.fr

tThese authors share first authorship

¥These authors share senior authorship

Specialty section:

This article was submitted to Molecular and Cellular Oncology,

a section of the journal

Frontiers in Oncology

Received: 02 March 2020 Accepted: 05 May 2020 Published: 30 July 2020

Citation:

Campion O, Al Khalifa T, Langlois B,

Thevenard-Devy J, Salesse $S$,

Savary K, Schneider C, Etique N,

Dedieu S and Devy J (2020)

Contribution of the Low-Density Lipoprotein Receptor Family to Breast

Cancer Progression.

Front. Oncol. 10:882.

doi: 10.3389/fonc.2020.00882

\section{Contribution of the Low-Density Lipoprotein Receptor Family to Breast Cancer Progression}

\author{
Océane Campion ${ }^{1,2 t}$, Tesnim Al Khalifa ${ }^{1,2 \dagger}$, Benoit Langlois ${ }^{1,2}$, Jessica Thevenard-Devy ${ }^{1,2}$, \\ Stéphanie Salesse ${ }^{1,2}$, Katia Savary ${ }^{1,2}$, Christophe Schneider ${ }^{1,2}$, Nicolas Etique ${ }^{1,2}$, \\ Stéphane Dedieu ${ }^{1,2 \ddagger}$ and Jérôme Devy ${ }^{1,2 * \neq}$ \\ ${ }^{1}$ Université de Reims Champagne-Ardenne (URCA), Reims, France, ${ }^{2}$ CNRS UMR 7369, Matrice Extracellulaire et \\ Dynamique Cellulaire, MEDyC, Reims, France
}

The low-density lipoprotein receptor (LDLR) family comprises 14 single-transmembrane receptors sharing structural homology and common repeats. These receptors specifically recognize and internalize various extracellular ligands either alone or complexed with membrane-spanning co-receptors that are then sorted for lysosomal degradation or cell-surface recovery. As multifunctional endocytic receptors, some LDLR members from the core family were first considered as potential tumor suppressors due to their clearance activity against extracellular matrix-degrading enzymes. LDLRs are also involved in pleiotropic functions including growth factor signaling, matricellular proteins, and cell matrix adhesion turnover and chemoattraction, thereby affecting both tumor cells and their surrounding microenvironment. Therefore, their roles could appear controversial and dependent on the malignancy state. In this review, recent advances highlighting the contribution of LDLR members to breast cancer progression are discussed with focus on (1) specific expression patterns of these receptors in primary cancers or distant metastasis and (2) emerging mechanisms and signaling pathways. In addition, potential diagnosis and therapeutic options are proposed.

Keywords: LDLR, breast cancer, microenvironment, biomarker, therapeutic targets

\section{THE LOW-DENSITY LIPOPROTEIN RECEPTOR FAMILY AND BREAST CANCER: A STATE OF ART}

The low-density lipoprotein receptor (LDLR) gene family encodes single-spanning transmembrane receptors usually referred to as LDLR-related proteins (LRPs). The 14 described members are LDLR, VLDLR, LRP1/CD91/A2MR, LRP1B, LRP2/megalin/GP330, LRP3, LRP4/MEGF7, LRP5, LRP6, LRP8/ApoER2, LRP10/LRP9, LRP11/SorLA LRP12/ST7, and LRAD3 (see Table 1). Despite various homology levels, most members are clustered type I receptors sharing structural motifs (e.g., cysteine-rich complement-type repeats), involved in specific recognition of extracellular ligands, EGF-precursor homologous and $\beta$-propeller domains critical for protein folding, and $\mathrm{pH}-$ dependent lysosomal release of ligands. The short intracellular tail encompasses motifs allowing the recruitment of scaffolds driving the endocytic machinery and intracellular signaling. The LDLR founding member was first identified as a frequently mutated etiological factor of familial hypercholesterolemia. LDLR functions were then extended to numerous physiopathological contexts such as vascular integrity, neurobiology, and cancer development due to their peculiar 
ability to control membrane compartmentalization of receptors and clearance of various classes of extracellular ligands. Some LRPs were thus implicated in the specific recognition of above 50 extracellular factors, among which several growth- or migrationregulatory molecules located in the tumor microenvironment (TME) of various cancers, including mammary cancers.

Breast cancer (BC) is one of the most diagnosed cancers among women worldwide and is the second-leading cause of cancer death. Based on their histological features, breast tumors are divided into two subtypes, in situ breast carcinoma and invasive breast carcinoma. The first subtype is subclassified as either ductal (DCIS) or lobular carcinoma in situ (LCIS). Invasive carcinomas are further categorized into several histological subtypes, such as infiltrating ductal, invasive lobular, ductal/lobular, mucinous (colloid), tubular, medullary, and papillary carcinomas. Classification of BC based on molecular components is more useful for treatment planning and development of targeted therapies. In this classification, $\mathrm{BC}$ is mainly divided into hormone-receptor positive $\left(\mathrm{ER}^{+} / \mathrm{PR}^{+}\right)$, human epidermal growth factor receptor-2 overexpressing $\left(\mathrm{HER} 2^{+}\right)$, and triple negative (TNBC). Over the past decades, breakthroughs have been made in $\mathrm{BC}$ treatment including surgery, radiotherapy, chemotherapy, endocrine therapy, targeted therapy, and immunotherapy. Despite all these therapeutic options, TNBC remains associated with poor outcomes and a historical lack of targeted therapies. Regarding metastases from BC, the most common first site of distant spread is bone (41\%), followed by lung (22\%), brain (7\%), and liver (7\%). The remaining $20 \%$ of patients have multiple metastatic sites (21). In this review, our focus will be on the role played by the members of the LDLR family in BC by examining specifically their implications within the tumor microenvironment. The clinical relevance of targeting these receptors for developing new targeted therapies will also be discussed.

\section{LRPS AND BREAST CANCER CELLS: A CLOSE AND COMPLEX RELATIONSHIP}

Obesity and hypercholesterolemia are risk factors for BC that negatively impact therapeutic efficacy $(22,23)$. Higher levels of plasmatic cholesterol, LDL (low-density lipoprotein), and triglycerides and low circulating levels of HDL are frequently found in patients with BC (24). Interestingly, LDL was reported to affect the sensitivity of tumor cells to radiotherapy in inflammatory BC (25). LDL could affect the adhesion of BC cells involved in cell migration and proliferation and a difference in the quantity and type of lipid synthesis and storage has been demonstrated in basal-like $\mathrm{ER}^{-}$compared to luminal $\mathrm{ER}^{+}$BC cells (26). Patients with BC usually exhibit elevated

\footnotetext{
Abbreviations: $\mathrm{BBB}$, blood-brain barrier; BC, breast cancer; DCIS, Ductal carcinoma in situ; ECM, extracellular matrix; EMT, epithelial-to-mesenchymal transition; ER, estrogen receptor; HDL, high-density lipoprotein; HER2, human epidermal growth factor receptor-2; LCIS, lobular carcinoma in situ; LDL, lowdensity lipoprotein; LDLR, low-density lipoprotein receptor; LRP, LDL receptorrelated protein; $\mathrm{PR}$, progesterone receptor; TME, tumor microenvironment; TNBC, triple-negative breast cancer; VDR, vitamin D receptor; VLDL, very low density lipoprotein.
}

serum levels of oxidized LDL, reported to induce structural DNA alterations, a decrease in DNA repair, and pro-oncogenic signaling pathways (1).

In mammary tumor tissues, LDLR expression is higher and cholesteryl ester accumulation is associated with an increase of Ki67 expression and poor clinical outcome $(27,28)$. BC cells express higher LRP1 and LDLR, allowing a better uptake of LDL-C from the blood (29). Cholesterol may also generate 27hydroxycholesterol, an estrogen mimetic involved in epithelialto-mesenchymal transition (EMT) in $\mathrm{ER}^{+} \mathrm{BC}$ cells $(30,31)$. In addition, LDLR and acyl-CoA:cholesterol acyltransferase- 1 are increased in HER2-positive and triple-negative tumors compared to luminal A tumors (1).

Among LDLR, the giant receptors are represented by LRP1, LRP1B, and LRP2, sharing strong structure homologies but showing discrepancies in terms of endocytic kinetics and expression pattern (32). LRP2/Megalin is required for the internalization of vitamin $\mathrm{D}$ and its activation to $1,25-\mathrm{OH}$ vitamin $\mathrm{D}$. A reduced expression was found in some $\mathrm{BC}$, leading to a decrease of its nuclear receptor VDR activation, which plays an important anti-proliferative role (33). LRP2 mRNA was also detected at fairly high levels in invasive BC but with extremely high variability (11).

LRP1B, a close homolog of LRP1, is among the top 10 significantly mutated genes in human cancer $(34,35)$. LRP1B is mutated in circulating tumor cells from BC and may participate in human mammary gland carcinogenesis (12). The nuclear localization of its intracellular domain is significantly related to poor prognosis in patients with invasive ductal breast carcinoma and to a significant decrease of both disease-free and overall survival in patients with luminal A type breast carcinoma (10).

LRP1 was initially identified as a tumor suppressor controlling, by endocytic clearance, the extracellular matrixdegrading enzymes in the microenvironment of various invasive tumors (36). In BC models, $\alpha 2$-macroglobulin/LRP1-dependent uptake of pepsin is involved in the control of the invasive potential of luminal and TNBC cells (37). However, other studies support a more complex view of LRP1 functions in tumor cells. The serine protease inhibitor PN-1/SerpinE2, which is highly expressed in $\mathrm{ER}^{-}$and high-grade $\mathrm{BC}$, stimulates lung metastasis of mammary tumor cells through LRP1-dependent secretion of MMP-9 (38). By contrast, SerpinE2 and LRP1 were identified among the genes induced by ZEB-1, an EMT driver that limits the expression of LRP1-targeting miRNAs, thereby triggering tumor cell autocrine factors that predict poor survival in early stage of BC (39). LRP1 can exert a dramatic control of tumor cell plasticity and migratory capacities. Its silencing in TNBC cells increased cellular rigidity, decreased cellular protrusions, and finally impaired migration (8). Converging data illustrate the important role of Hsp90 $\alpha$ binding to LRP1 during EMT-related events in BC (40-43). Hypoxia leads to HIF1- $\alpha$-dependent secretion of Hsp $90 \alpha$ by TNBC cells. Its specific binding to LRP1 stimulates tumor development and metastatic lung colonization (42). This interaction and subsequent pro-metastatic signals are reinforced by clusterin in both luminal and TNBC models (43). Interestingly, within extracellular space, Hsp90 $\alpha$ is absent from the normal microenvironment, suggesting promising 
TABLE 1 | The 14 members of the low-density lipoprotein receptor family and their involvement in breast cancer.

\begin{tabular}{|c|c|c|c|c|}
\hline LRP isotype & Alternative name & MW (kDa) & Tissue distribution & How involved in breast cancer \\
\hline LDLR & & $120-160$ & Ubiquitous & $\begin{array}{l}\text { - Overexpressed in HER2 }{ }^{+} \text {and TNBC (MDA-MB-231) (1) } \\
\text { - Overexpression accelerates LDL cholesterol-mediated } \\
\text { BC growth in mouse models of hyperlipidemia (2) }\end{array}$ \\
\hline $\begin{array}{l}\text { VLDL-R } \\
\text { (type II) }\end{array}$ & & 96 & $\begin{array}{l}\text { Abundant in heart, skeletal muscle, ovary and } \\
\text { kidney }\end{array}$ & $\begin{array}{l}\text { - Up-regulated expression correlates with BC } \\
\text { metastasis }(3) \\
\text { - Promotes BC cell migration by up-regulating VEGF, } \\
\text { MMP2 and MMP7 }(4) \\
\text { - Survival factor in } \operatorname{TNBC}(5,6)\end{array}$ \\
\hline LRAD3 & Ldlrad3 & 50 & Neurons & None \\
\hline LRP1 & a2MR APOER CD91 & 600 & $\begin{array}{l}\text { Ubiquitous (liver, brain, adipose tissue, } \\
\text { fibroblasts and tissue stroma) }\end{array}$ & $\begin{array}{l}\text { - Overexpressed in aggressive HER2 }{ }^{+} \text {and TNBC and } \\
\text { associated with increased invasion (7) } \\
\text { - Stimulates TNBC migration (8) } \\
\text { - C766T polymorphism is suspected to increase risk of } \\
\text { BC development (9) }\end{array}$ \\
\hline LRP2 & Megalin GP330 & $517 / 600$ & Placenta, kidney, mammary epithelial cells & $\begin{array}{l}\text { - High mRNA levels in invasive BC (11) } \\
\text { - Mutated in circulating tumor cells from BC (12) } \\
\text { - Upregulated in T-47D (13) }\end{array}$ \\
\hline LRP3 & hLRP105 & 105 & $\begin{array}{l}\text { Widely expressed (ovary, heart, brain, liver, } \\
\text { pancreas, prostate and small intestine, skeletal } \\
\text { muscle) }\end{array}$ & ND \\
\hline LRP8 & APOER2 & 106 & Brain, placenta, platelets & $\begin{array}{l}\text { - Overexpressed in TNBC and ER- BC }(18,19) \\
\text { - Positive regulator of BC stem cells in TNBC, supports } \\
\text { chemoresistance and metastasis (18) } \\
\text { - Suggested as novel therapeutic target in TNBC (6) }\end{array}$ \\
\hline LRP10 & LRP9 in mouse & 76 & $\begin{array}{l}\text { Ubiquitous (Leukocyte, lung, placenta, small } \\
\text { intestine, liver, kidney, spleen, thymus, colon, } \\
\text { skeletal muscle, heart) }\end{array}$ & ND \\
\hline LRP11 & sorLA LR11 & 53 & $\begin{array}{l}\text { Substantial levels in kidney, testis, ovary, lymph } \\
\text { nodes, vascular smooth muscle cells and } \\
\text { nervous system }\end{array}$ & - Drives resistance to anti-HER2 therapy (20) \\
\hline LRP12 & ST7 & 94 & $\begin{array}{l}\text { Heart, skeletal muscle, brain, lung, placenta } \\
\text { and pancreas }\end{array}$ & ND \\
\hline
\end{tabular}

The family core members are underlined in green, the structurally distant members are in blue, and the most distant members are in orange. ND: not determined. 
opportunities for targeted therapy (42). These studies underline the versatility of LRP1 functions in breast TME and support ongoing research to identify the specific molecular interfaces mobilized by the receptor that could be targeted to control aggressive behavior of tumor cells. A less characterized member of LRPs, SorLA/LRP11, was recently involved in the endocytic trafficking of HER2 (20). The depletion of SorLA was reported to affect lysosomal function and sensitize HER2-overexpressing cells resistant to targeted therapy. Its targeting could therefore affect compartmentalized pools of oncogenic receptors and restore efficacy of conventional treatments.

LRP5 and LRP6, as co-receptors of the Wnt/ $\beta$-catenin pathway, are directly involved in breast tumorigenesis. Wnt ligands such as frizzled homolog 7 and LRP6 are overexpressed in TNBC (44), whereas Wnt antagonists are frequently silenced by methylation in BC (45). Blockade or silencing of LRP6 in SUM1315 basal BC cells results in a re-expression of epithelial markers and a decreased capacity to self-renew and metastasize (46). Similarly, LRP6 downregulation in MDA-MB-231 decreases the pool of BC stem cells (17). These effects are more pronounced on TNBC cell migration and invasion (47). The use of benzimidazole compounds on TNBC cells exerts anticancer activity by inhibiting the $\mathrm{Wnt} / \beta$-catenin pathway. Prodigiosin and other compounds decrease the phosphorylation of LRP6 (active form), and inhibit the activation of mTORC and Wnt/ $\beta$ catenin signaling (48-52). The disruption of lipid rafts in TNBC cells is associated with a decrease of LRP6 and $\beta$-catenin expression, cell proliferation, and migration (53). Besides this Wnt/Bcatenin canonical pathway, LRP5 was also reported to be involved in the uptake of glucose in mammary epithelial cells, through Apolipoprotein E (ApoE) binding. The glucose uptake is essential for regulating the growth rate of these cells (16). A soluble LRP6 ectodomain can prevent tumor progression, by inhibiting cell migration and metastasis, by limiting the Frzmediated non-canonical pathway activation in breast tumor cells (54).

The function of LRP8/ApoER2, strongly expressed in ER negative breast tumors was recently described in breast tumor initiating cells, which constitute a clinical challenge of the pathology (18). Interestingly, its depletion impairs TNBC cell proliferation and promotes apoptosis (19). LRP8 depletion also leads to $\mathrm{Wnt} / \beta$-catenin signaling inhibition, decreases the pool of $\mathrm{BC}$ cells, limits their tumorigenic potential in murine xenografts, and finally restores TNBC cell sensitivity to chemotherapy (18). An overview of the complex and multiple LRPs-mediated signaling pathways is shown in Figure 1.

\section{FUNCTIONAL INTERPLAY BETWEEN LRPS AND CELLS WITHIN THE TUMOR MICROENVIRONMENT}

The breast TME encompasses multiple cell types including fibroblasts, immune cells, adipocytes, and endothelial cells (55). In human breast tumors, fibroblasts are the most abundant stromal cells and high levels of LRP1 expression was reported (56). In fibroblasts, LRP1 binds to CTGF, PDGF, and TGF $\beta$ and interacts with their respective receptors, thereby modulating their mitogenic or contractile capacities (57-61). Similarly, to LRP1, LRP6 interacts closely with PDGFR $\beta$ and TGF- $\beta$ RI in pericytes and is involved in their trans-differentiation into myofibroblasts in response to TGF $\beta$ or CTGF. Therefore, it stimulates the PDGF-BB-dependent proliferation of established myofibroblasts via $\beta$-catenin-independent mechanisms (62). Likewise, Wnt7a secreted by aggressive breast tumor cells promotes the activation of stromal fibroblasts through TGF $\beta$ signaling (63). In cancerassociated fibroblast from mammary tumors, the stabilization of LRP6 at cell surface by DKK3 stimulates $\beta$-catenin and YAP/TAZ signals, promoting pro-tumorigenic functions such as ECM stiffening (64). Interestingly, pro-cath-D hypersecreted by cancer cells in the breast TME stimulates fibroblast outgrowth by inhibiting the release of LRP1 $\beta$ (intracellular domain), which is able to regulate gene transcription (65).

Adipocytes are mainly engaged during BC progression through a metabolic crosstalk with adjacent tumor cells and adopt a modified phenotype called cancer-associated adipocytes (66). Resulting dysfunctional adipocytes overexpressed fatty acid, cholesterol, triglycerides, hormones, but also adipokines, inflammatory cytokines, and proteases that are linked to cancer progression (66). LRP-1 is highly expressed in preadipocytes and is involved in adipocyte differentiation, especially through its regulation of peroxisome proliferator-activated receptor $\gamma$ (67). LRP1 has also been demonstrated to be upregulated in obese mouse adipocytes and obese human adipose tissues (67) and to regulate insulin receptor and GLUT4 trafficking and activation $(68,69)$. Through modulation of Wnt5a signaling, LRP1 controls cholesterol storage and fatty acid synthesis during adipocyte differentiation (70). An attenuated endocytosis of apoA5 by adipocytes was demonstrated in both adipose tissue from obese patients and insulin-resistant adipocytes. The mechanism underlying this phenomenon might be related to a reduced endocytic activity of LRP1 and/or an attenuated insulindependent movement of LRP1 from intracellular structures to the cell surface (71). These mechanisms may lead to excessive augmentation of triglyceride storage and abnormal metabolism of adipocytes, hence promoting the development of obesity and obesity-associated disorders such as BC.

LRP1 is also abundantly expressed by various immune cells and its function in HSP-mediated antigen presentation and subsequent innate immune response is well described in macrophages and dendritic cells (72). LRP1 also inhibits macrophage-driven inflammation by decreasing cell-surface abundance of the TNF receptor-1 and I 1 -B kinase/NF$\kappa \mathrm{B}$ intracellular activation (73). By contrast, production of sLRP1 (shed or soluble LRP1) by macrophages induces proinflammatory factor synthesis such as IL-10, TNF- $\alpha$, and MCP1 (74). Macrophage inflammatory protein-1a/CCL3, known to amplify inflammation, is overproduced in the absence of LRP1 in myeloid cells, leading to enhanced CCR5-expressing monocyte recruitment to tumors and cancer angiogenesis (75).

Recent studies have demonstrated the crucial angiomodulatory actions of LRP family members in various solid tumors, including BCs $(39,51,76-79)$. LDL and VLDL (very low density lipoprotein) are involved in the secretion of diffusible 


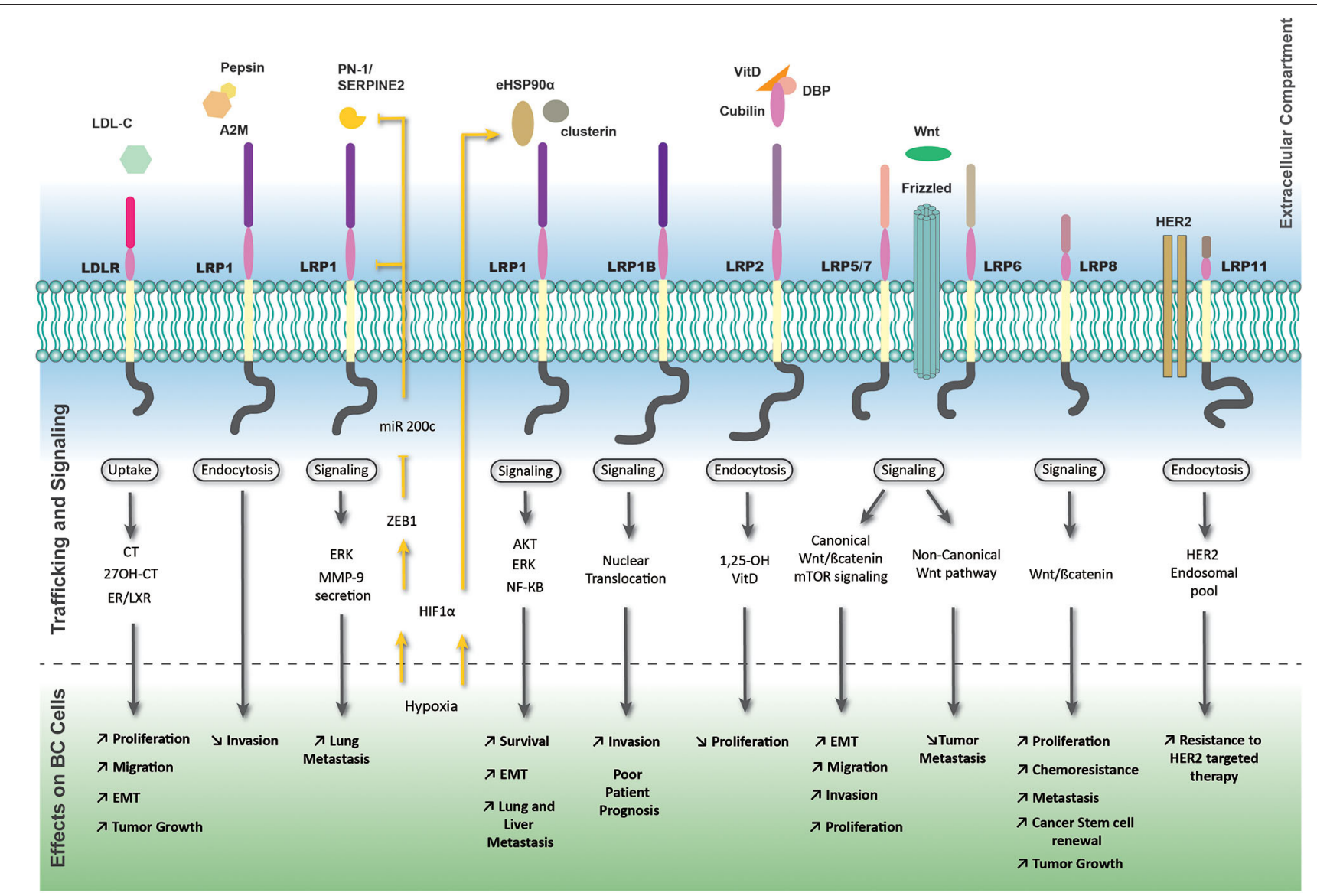

FIGURE 1 | LRP-mediated signaling pathways and trafficking in breast tumor cells. The most important members of the LDLR family exhibiting effects on breast cancer cells are represented with their associated extracellular ligands. Outside-in and inside-out pathways are represented by black and yellow arrows or lines, respectively. The yellow strikethrough line indicates an inhibition. A2M, alpha-2 macroglobulin; CT, cholesterol; ER, estrogen receptor; LXR, liver X receptor; VitD, vitamin D.

angiogenic factors by BC cells, such as amphiregulin (79). Moreover, the binding of Wnt3a to LRP6 stimulates VEGF production by TNBC cells (51). The stoichiometry of Wnt ligands and their secreted regulators such as Dickkopfs (DKK) seems instrumental to fine-tune LRP5/6 functions in the TME. DKK1 was indeed described as anti-angiogenic, whereas DKK2 binding to LRP6 triggers potent induction of endothelial cell sprouting (80). LRP1 is widely expressed in various endothelial cells and its specific binding to tPA alone or complexed with uPA/PAI-1 induces vascular permeability in the blood-brain barrier (BBB) or in lung microvasculature, two major sites of BC cell metastatic homing $(81,82)$. LRP1 controls multiple aspects of endothelial cell metabolism (83) and participates to the control of intercellular junctionality, morphogenesis, and proliferation $(81,84,85)$. Interestingly and as stated above, during epithelial-to-mesenchymal transition in breast tumors, LRP1 expression was derepressed through ZEB-1-dependent inhibition of LRP1-targeting miRNAs, thereby contributing to vascular mimicry of breast tumor cells (39). The induction of this endocytic receptor could thus reinforce endothelial interface of breast tumor cells and facilitate their metastatic dissemination.

\section{CLINICAL SIGNIFICANCE OF LRPS AS BIOMARKER IN THE CONTEXT OF BREAST TUMORS}

A large-scale study conducted on solid tumors indicates that mostly LDLR mRNA are overexpressed in breast invasive carcinomas with LRP2 mRNA being the most expressed, but no correlation with patient survival was observed (11). Only a few studies are focused on LRP1 expression in BC patient samples. LRP1 was first immunohistochemically studied in fresh frozen tissue from primary invasive breast carcinomas, ductal in situ carcinomas, and auxiliary lymph-node metastases in 1996 (56). LRP1 staining appeared intense in all stromal fibroblasts both outside and within the tumor tissue and scattered in macrophages and mast cells. Interestingly, epithelial cells, endothelial cells, and lymphocytes appeared negative for LRP1. A more recent immunohistochemistry study of LRP1 expression, performed on infiltrating ductal breast carcinomas, brought different results as cytoplasmic LRP1 overexpression was identified in tumor cells in addition to non-neoplastic stromal cells, whereas normal ductal cells were always negative (7). Concerning LRP1 polymorphism, 
although C766T mutation was firstly reported as significantly higher in patients with BC (9), the increased risk of BC development associated to LRP1 polymorphism is not definitely established. Of note, neoadjuvant chemotherapy in BC did not impair LRP1 expression (28).

\section{A BETTER UNDERSTANDING OF LRP FUNCTIONALITIES MAY LEAD TO EFFICIENT THERAPEUTIC STRATEGIES}

Therapeutic approaches involving LRPs developed in oncology, particularly in BC, aim to address the endocytic properties of these receptors as vectorization tools. One of the remaining therapeutic concerns for BC patients is related to metastases. Brain metastases occur in about $15-30 \%$ of women with stage IV BC. The targeting of the BBB, formed by endothelial cells, astrocytes, and pericytes embedded in the capillary basement membrane, remains critical for treating brain metastases. As LRP1 transports ligands such as $\beta$-Amyloid or tPA across the $\mathrm{BBB}$ and is expressed at high levels in this tissue (86), it appears as a promising candidate for targeted therapy against metastatic $\mathrm{BC}$ cells. In this context, the main therapeutic approaches use the Angiopep-2, an LRP1 binding peptide first identified by Demeule and colleagues (87). Combined with three paclitaxel residues, this molecule (namely, GRN1005, formerly known as ANG1005) binds to LRP1, crosses the BBB, and allows a better drug delivery in the brain compartment $(78,87)$. Phase I/II clinical trials with ANG1005/GRN1005 show that treatment is safe and brings clinical benefit for both peripheral metastatic BC and brain metastasis, even if the tumor had previously developed resistance to conventional taxanes. Interestingly, an open-label Phase III study will start in 2020 to investigate whether ANG1005 can prolong patient survival in HER2-negative BC patients with newly diagnosed leptomeningeal disease and previously treated brain metastases (NCT03613181). Angiopep-2 can also be useful to target BC cells overexpressing LRP1. For instance, Angiopep-2 was used to decorate nanoparticules combined with doxycycline (Angio-DOX-DGL-GNP) in TNBC to facilitate the drug penetration and accumulation in BC cells (88).

The endocytic properties of LRP2 have also been used to improve the effectiveness of anticancer drugs in resistant BC cells (89). In this context, lipid-polyethylenimine hybrid nanocarriers decorated with apolipoprotein E (Ap-LPN) were developed for improving siRNA delivery against clusterin in MCF7 BC cells, leading to increased cell chemosensitization toward paclitaxel.

Another strategy of tumor targeting was used with the NT4 peptide, a tetrabranched peptide from the human neurotensin, capable of binding LRP1 and LRP6 by mimicking ApoE and midkine heparin binding site (90). Depau and collaborators showed that methotrexate conjugated with NT4 can overcome drug resistance in methotrexate-resistant human BC cells (91). NT4 conjugated with other drugs (NT4-paclitaxel, NT4-5FdU) were tested in various animal models of human cancer, including an orthotopic mouse model of human BC, leading to improved drug activity as compared to unconjugated counterpart (92-94).

More recently, some LRPs have been identified as direct molecular targets for BC. LRP6 is probably the most promising target in the TNBC with its overexpression leading to Wnt signaling pathway activation together with tumorigenesis promotion (5). Several drugs such as salinomycin, prodigiosin, and niclosamide indeed induce LRP6 phosphorylation and degradation leading to decreased tumor growth $(49,50,95)$. Ren and collaborators have suggested that soluble LRP6 ectodomain could also be used as an innovative anti-metastatic drug (54).

\section{CONCLUSION AND SUBJECTIVE POINTS OF VIEW}

Receptors from the LDLR family are increasingly emerging as key relevant biomarkers in oncology and potential therapeutic targets. Their multiple implications within the TME, variable expression related to tumor stages, together with molecular versatility, constitute the main challenges to better understand their functionalities. In breast cancer, scientific evidence is fragmented, sometimes contradictory, and only a few clinical data are available. Potential prognostic value of these receptors is still unclear, thus preventing from demonstrating clinical benefits. Additional studies will be necessary to establish a link between LRPs and some events promoting obesity or metabolic diseases, particularly to improve the treatment of $\mathrm{BC}$ in postmenopausal patients. LRP1 is likely to be the most promising receptor because it constitutes an efficient drug carrier within tumor cells. Very promising trials are ongoing in HER2-negative BC patients with metastasis. In addition, LRP1 could also be considered as an attractive therapeutic target in TNBC. However, its high molecular weight, intricate regulation, and sub-cellular localization together with its ability to bind multiple extracellular ligands within the same clusters, make current research extremely complex and can lead to contradictory conclusions. The use of more advanced in vitro multi-cellular and 3D tumor-based systems (tumoroïds) with patient-derived cells will be key to deeper understand the functionality of this receptor. In the coming years and in order to consider LRP1 as an innovative vectorization tool, the approach should be focused on the endocytic properties of overexpressed LRP1 rather than on the modulation (e.g., inhibition or reduction) of LRP1 expression.

\section{AUTHOR CONTRIBUTIONS}

All authors listed have made a substantial, direct and intellectual contribution to the work, and approved it for publication.

\section{ACKNOWLEDGMENTS}

We acknowledge Arlette Thomachot and Dr. Laetitia Devy for editorial assistance. 


\section{REFERENCES}

1. Cedo L, Reddy ST, Mato E, Blanco-Vaca F, Escola-Gil JC. HDL and IDL: potential new players in breast cancer development. J Clin Med. (2019) 8:853. doi: $10.3390 /$ jcm 8060853

2. Gallagher EJ, Zelenko Z, Neel BA, Antoniou IM, Rajan L, Kase N, et al. Elevated tumor IDLR expression accelerates IDL cholesterol-mediated breast cancer growth in mouse models of hyperlipidemia. Oncogene. (2017) 36:64626471. doi: 10.1038/onc.2017.247

3. He L, Lu Y, Wang P, Zhang J, Yin C, Qu S. Up-regulated expression of type iI very low density lipoprotein receptor correlates with cancer metastasis and has a potential link to $\beta$-catenin in different cancers. BMC cancer. (2010) 10:601. doi: 10.1186/1471-2407-10-601

4. He L, Lu Y, Guo J. Type iI vLDLR promotes cell migration by up-regulation of vEGF, mMP2 and mMP7 in breast cancer cells. Chin Germ J Clin Oncol. (2013) 12:374-8. doi: 10.1007/s10330-013-1218-7

5. Roslan Z, Muhamad M, Selvaratnam L, Ab-Rahim S. The roles of low-Density lipoprotein receptor-Related proteins 5, 6, and 8 in cancer: a Review. J Oncol. (2019) 2019:4536302. doi: 10.1155/2019/4536302

6. Arun B, Bayraktar S, Shiang C, Qi Y, Wang B, Angelica GB, et al. High throughput siRNA screen identifies LRP8 as druggable metabolic regulator in TripleNegative breast cancer. SM J Hematol Oncol. (2016) 1:1003.

7. Catasus L, Gallardo A, Llorente-Cortes V, Escuin D, Munoz J, Tibau A, et al. Low-density lipoprotein receptor-related protein 1 is associated with proliferation and invasiveness in her2/neu and triple-negative breast carcinomas. Hum Pathol. (2011) 42:1581-8. doi: 10.1016/j.humpath.2011.01.011

8. Berquand A, Meunier M, Thevenard-Devy J, Ivaldi C, Campion O, Dedieu S, et al. A gentle approach to investigate the influence of IRP1 silencing on the migratory behavior of breast cancer cells by atomic force microscopy and dynamic cell studies. Nanomedicine. (2019) 18:35970. doi: 10.1016/j.nano.2018.10.012

9. Benes P, Jurajda M, Zaloudik J, Izakovicova-Holla L, Vacha J. C766T lowdensity lipoprotein receptor-related protein 1 (LRP1) gene polymorphism and susceptibility to breast cancer. Breast Cancer Res. (2003) 5:R7781. doi: 10.1186/bcr591

10. Asano Y, Takeuchi T, Okubo H, Saigo C, Kito Y, Iwata Y, et al. Nuclear localization of $\mathrm{IDL}$ receptor-related protein 1B in mammary gland carcinogenesis. J Mol Med (Berl). (2019) 97:257-68. doi: 10.1007/s00109-018-01732-2

11. Gonias SL, Karimi-Mostowfi N, Murray SS, Mantuano E, Gilder AS. Expression of IDL receptor-related proteins (LRPs) in common solid malignancies correlates with patient survival. PLoS ONE. (2017) 12:e0186649. doi: 10.1371/journal.pone.0186649

12. Wang Y, Guo L, Feng L, Zhang W, Xiao T, Di X, et al. Single nucleotide variant profiles of viable single circulating tumour cells reveal cTC behaviours in breast cancer. Oncol Rep. (2018) 39:2147-2159. doi: 10.3892/or.2018.6325

13. Chlon TM, Taffany DA, Welsh J, Rowling MJ. Retinoids modulate expression of the endocytic partners megalin, cubilin, and disabled-2 and uptake of vitamin d-binding protein in human mammary cells. J Nutr. (2008) 138:13238. doi: 10.1093/jn/138.7.1323

14. Lindvall C, Zylstra CR, Evans N, West RA, Dykema K, Furge KA, et al. The wnt co-receptor lrp6 is required for normal mouse mammary gland development. PLoS ONE. (2009) 4:e5813. doi: 10.1371/journal.pone.0005813

15. Maubant S, Tahtouh T, Brisson A, Maire V, Némati F, Tesson B, et al. LRP5 regulates the expression of sTK40, a new potential target in triple-negative breast cancers. Oncotarget. (2018) 9:22586. doi: 10.18632/oncotarget.25187

16. Chin EN, Martin JA, Kim S, Fakhraldeen SA, Alexander CM. Lrp5 has a wntIndependent role in glucose uptake and growth for mammary epithelial cells. Mol Cell Biol. (2015) 36:871-85. doi: 10.1128/MCB.00800-15

17. Ibrahim SA, Hassan H, Vilardo L, Kumar SK, Kumar AV, Kelsch R, et al. Syndecan-1 (CD138) modulates triple-negative breast cancer stem cell properties via regulation of IRP-6 and iL-6-mediated sTAT3 signaling. PLoS ONE. (2013) 8:e85737. doi: 10.1371/journal.pone. 0085737

18. Lin CC, Lo MC, Moody R, Jiang H, Harouaka R, Stevers N, et al. Targeting IRP8 inhibits breast cancer stem cells in triple-negative breast cancer. Cancer Lett. (2018) 438:165-73. doi: 10.1016/j.canlet.2018.09.022
19. Maire V, Mahmood F, Rigaill G, Ye M, Brisson A, Nemati F, et al. LRP8 is overexpressed in estrogen-negative breast cancers and a potential target for these tumors. Cancer Med. (2019) 8:325-36. doi: 10.1002/cam4.1923

20. Pietila M, Sahgal P, Peuhu E, Jantti NZ, Paatero I, Narva E, et al. SORLA regulates endosomal trafficking and oncogenic fitness of hER2. Nat Commun. (2019) 10:2340. doi: 10.1038/s41467-019-10275-0

21. Berman AT, Thukral AD, Hwang WT, Solin LJ, Vapiwala N. Incidence and patterns of distant metastases for patients with early-stage breast cancer after breast conservation treatment. Clin Breast Cancer. (2013) 13:8894. doi: 10.1016/j.clbc.2012.11.001

22. Liu J, Xu A, Lam KS, Wong NS, Chen J, Shepherd PR, et al. Cholesterol-induced mammary tumorigenesis is enhanced by adiponectin deficiency: role of IDL receptor upregulation. Oncotarget. (2013) 4:180418. doi: 10.18632/oncotarget.1364

23. Lee K, Kruper L, Dieli-Conwright CM, Mortimer JE. The impact of obesity on breast cancer diagnosis and treatment. Curr Oncol Rep. (2019) 21:41. doi: 10.1007/s11912-019-0787-1

24. Li X, Liu ZL, Wu YT, Wu H, Dai W, Arshad B, et al. Status of lipid and lipoprotein in female breast cancer patients at initial diagnosis and during chemotherapy. Lipids Health Dis. (2018) 17:91. doi: 10.1186/s12944-018-0745-1

25. Wolfe AR, Atkinson RL, Reddy JP, Debeb BG, Larson R, Li L, et al. Highdensity and very-low-density lipoprotein have opposing roles in regulating tumor-initiating cells and sensitivity to radiation in inflammatory breast cancer. Int J Radi Oncol. (2015) 91:1072-80. doi: 10.1016/j.ijrobp.2014.12.039

26. Guan X, Liu Z, Zhao Z, Zhang X, Tao S, Yuan B, et al. Emerging roles of lowdensity lipoprotein in the development and treatment of breast cancer. Lipids Health Dis. (2019) 18:137. doi: 10.1186/s12944-019-1075-7

27. de Gonzalo-Calvo D, Lopez-Vilaro L, Nasarre L, Perez-Olabarria M, Vazquez T, Escuin D, et al. Intratumor cholesteryl ester accumulation is associated with human breast cancer proliferation and aggressive potential: a molecular and clinicopathological study. BMC Cancer. (2015) 15:460. doi: 10.1186/s12885-015-1469-5

28. Pires LA, Hegg R, Freitas FR, Tavares ER, Almeida CP, Baracat EC, et al. Effect of neoadjuvant chemotherapy on low-density lipoprotein (LDL) receptor and IDL receptor-related protein 1 (LRP-1) receptor in locally advanced breast cancer. Braz J Med Biol Res. (2012) 45:55764. doi: 10.1590/S0100-879X2012007500068

29. dos Santos CR, Domingues G, Matias I, Matos J, Fonseca I, de Almeida JM, et al. LDL-cholesterol signaling induces breast cancer proliferation and invasion. Lipids Health Dis. (2014) 13:16. doi: 10.1186/1476-511X-13-16

30. Torres CG, Ramirez ME, Cruz P, Epunan MJ, Valladares LE, SierraltaWD. 27hydroxycholesterol induces the transition of MCF7 cells into a mesenchymal phenotype. Oncol Rep. (2011) 26:389-97. doi: 10.3892/or.2011.1284

31. Cruz P, Torres C, Ramirez ME, Epunan MJ, Valladares LE, Sierralta WD. Proliferation of human mammary cancer cells exposed to 27-hydroxycholesterol. Exp Ther Med. (2010) 1:531-6. doi: 10.3892/etm_00000084

32. Liu CX, Li Y, Obermoeller-McCormick LM, Schwartz AL, Bu G. The putative tumor suppressor IRP1B, a novel member of the low density lipoprotein (LDL) receptor family, exhibits both overlapping and distinct properties with the IDL receptor-related protein. J Biol Chem. (2001) 276:2888996. doi: 10.1074/jbc.M102727200

33. Cabezas F, Farfan P, Marzolo MP. Participation of the sMAD2/3 signalling pathway in the down regulation of megalin/LRP2 by transforming growth factor beta (TGF-ss1). PLoS One. (2019) 14:e0213127. doi: 10.1371/journal.pone.0213127

34. Knisely JM, Li Y, Griffith JM, Geuze HJ, Schwartz AL, Bu G. Slow endocytosis of the $1 \mathrm{DL}$ receptor-related protein $1 \mathrm{~B}$ : implications for a novel cytoplasmic tail conformation. Exp Cell Res. (2007) 313:3298307. doi: 10.1016/j.yexcr.2007.05.026

35. Chen H, Chong W, Wu Q, Yao Y, Mao M, Wang X. Association of IRP1B mutation with tumor mutation burden and outcomes in melanoma and nonsmall cell lung cancer patients treated with immune check-Point blockades. Front Immunol. (2019) 10:1113. doi: 10.3389/fimmu.2019.01523

36. Dedieu S, Langlois B. LRP-1: a new modulator of cytoskeleton dynamics and adhesive complex turnover in cancer cells. Cell Adh Migr. (2008) 2:7780. doi: $10.4161 /$ cam.2.2.6374 
37. Kang HS, Kim J, Lee HJ, Kwon BM, Lee DK, Hong SH. LRP1dependent pepsin clearance induced by 2'-hydroxycinnamaldehyde attenuates breast cancer cell invasion. Int J Biochem Cell Biol. (2014) 53:15-23. doi: 10.1016/j.biocel.2014.04.021

38. Fayard B, Bianchi F, Dey J, Moreno E, Djaffer S, Hynes NE, et al. The serine protease inhibitor protease nexin-1 controls mammary cancer metastasis through IRP-1-mediated mMP-9 expression. Cancer Res. (2009) 69:56908. doi: 10.1158/0008-5472.CAN-08-4573

39. Langer EM, Kendsersky ND, Daniel CJ, Kuziel GM, Pelz C, Murphy $\mathrm{KM}$, et al. ZEB1-repressed microRNAs inhibit autocrine signaling that promotes vascular mimicry of breast cancer cells. Oncogene. (2018) 37:1005019. doi: 10.1038 /onc.2017.356

40. Boel NM, Hunter MC, Edkins AL. LRP1 is required for novobiocin-mediated fibronectin turnover. Sci Rep. (2018) 8:11438. doi: 10.1038/s41598-018-29531-2

41. Dong H, Zou M, Bhatia A, Jayaprakash P, Hofman F, Ying Q, et al. Breast cancer mDA-MB-231 cells use secreted heat shock protein-90alpha (Hsp90alpha) to survive a hostile hypoxic environment. Sci Rep. (2016) 6:20605. doi: 10.1038/srep20605

42. Sahu D, Zhao Z, Tsen F, Cheng CF, Park R, Situ AJ, et al. A potentially common peptide target in secreted heat shock protein-90alpha for hypoxiainducible factor-1alpha-positive tumors. Mol Biol Cell. (2012) 23:60213. doi: 10.1091/mbc.e11-06-0575

43. Tian Y, Wang C, Chen S, Liu J, Fu Y, Luo Y. Extracellular hsp90alpha and clusterin synergistically promote breast cancer epithelial-tomesenchymal transition and metastasis via IRP1. J Cell Sci. (2019) 132:228213. doi: 10.1242/jcs.228213

44. Yang L, Wu X, Wang Y, Zhang K, Wu J, Yuan YC, et al. FZD7 has a critical role in cell proliferation in triple negative breast cancer. Oncogene. (2011) 30:4437-46. doi: 10.1038/onc.2011.145

45. Suzuki H, Toyota M, Carraway H, Gabrielson E, Ohmura T, Fujikane T, et al. Frequent epigenetic inactivation of wnt antagonist genes in breast cancer. $\mathrm{Br} \mathrm{J}$ Cancer. (2008) 98:1147-56. doi: 10.1038/sj.bjc.6604259

46. DiMeo TA, Anderson K, Phadke P, Fan C, Perou CM, Naber S, et al. A novel lung metastasis signature links wnt signaling with cancer cell self-renewal and epithelial-mesenchymal transition in basal-like breast cancer. Cancer Res. (2009) 69:5364-73. doi: 10.1158/0008-5472.CAN-08-4135

47. Ma J, Lu W, Chen D, Xu B, Li Y. Role of wnt co-Receptor lRP6 in triple negative breast cancer cell migration and invasion. J Cell Biochem. (2017) 118:2968-76. doi: 10.1002/jcb.25956

48. Gangrade A, Pathak V, Augelli-Szafran CE, Wei HX, Oliver P, Suto $\mathrm{M}$, et al. Preferential inhibition of wnt/beta-Catenin signaling by novel benzimidazole compounds in triple-negative breast cancer. Int J Mol Sci. (2018) 19:1524. doi: 10.3390/ijms19051524

49. Wang Z, Li B, Zhou L, Yu S, Su Z, Song J, et al. Prodigiosin inhibits wnt/betacatenin signaling and exerts anticancer activity in breast cancer cells. Proc Natl Acad Sci USA. (2016) 113:13150-5. doi: 10.1073/pnas.1616336113

50. Lu W, Li Y. Salinomycin suppresses IRP6 expression and inhibits both wnt/beta-catenin and $\mathrm{mTORC} 1$ signaling in breast and prostate cancer cells. $J$ Cell Biochem. (2014) 115:1799-807. doi: 10.1002/jcb.24850

51. Zhang J, Yang Z, Li P, Bledsoe G, Chao L, Chao J. Kallistatin antagonizes wnt/beta-catenin signaling and cancer cell motility via binding to low-density lipoprotein receptor-related protein 6. Mol Cell Biochem. (2013) 379:295301. doi: 10.1007/s11010-013-1654-2

52. Lu W, Lin C, Li Y. Rottlerin induces wnt co-receptor lRP6 degradation and suppresses both wnt/beta-catenin and mTORC1 signaling in prostate and breast cancer cells. Cell Signal. (2014) 26:1303-9. doi: 10.1016/j.cellsig.2014.02.018

53. Badana AK, Chintala M, Gavara MM, Naik S, Kumari S, Kappala VR, et al. Lipid rafts disruption induces apoptosis by attenuating expression of IRP6 and survivin in triple negative breast cancer. Biomed Pharmacother. (2018) 97:359-68. doi: 10.1016/j.biopha.2017.10.045

54. Ren DN, Chen J, Li Z, Yan H, Yin Y, Wo D, et al. LRP5/6 directly bind to frizzled and prevent frizzled-regulated tumour metastasis. Nat Commun. (2015) 6:6906. doi: 10.1038/ncomms7906

55. Soysal SD, Tzankov A, Muenst SE. Role of the tumor microenvironment in breast cancer. Pathobiology. (2015) 82:142-52. doi: 10.1159/000430499
56. Christensen L, Wiborg Simonsen AC, Heegaard CW, Moestrup SK, Andersen JA, Andreasen PA. Immunohistochemical localization of urokinase-type plasminogen activator, type-1 plasminogenactivator inhibitor, urokinase receptor and alpha(2)-macroglobulin receptor in human breast carcinomas. Int J Cancer. (1996) 66:44152. doi: 10.1002/(SICI)1097-0215(19960516)66:4<441::AID-IJC6>3.0.CO;2-W

57. Newton CS, Loukinova E, Mikhailenko I, Ranganathan S, Gao Y, Haudenschild C, et al. Platelet-derived growth factor receptor-beta (PDGFR-beta) activation promotes its association with the low density lipoprotein receptor-related protein (LRP). Evidence for co-receptor function. J Biol Chem. (2005) 280:27872-8. doi: 10.1074/jbc.M5054 10200

58. Yang M, Huang H, Li J, Li D, Wang H. Tyrosine phosphorylation of the IDL receptor-related protein (LRP) and activation of the eRK pathway are required for connective tissue growth factor to potentiate myofibroblast differentiation. FASEB J. (2004) 18:1920-1. doi: 10.1096/fj.04-2357fje

59. Muratoglu SC, Mikhailenko I, Newton C, Migliorini M, Strickland DK. Low density lipoprotein receptor-related protein 1 (LRP1) forms a signaling complex with platelet-derived growth factor receptor-beta in endosomes and regulates activation of the mAPK pathway. J Biol Chem. (2010) 285:1430817. doi: 10.1074/jbc.M109.046672

60. Schnieder J, Mamazhakypov A, Birnhuber A, Wilhelm J, Kwapiszewska G, Ruppert C, et al. Loss of IRP1 promotes acquisition of contractilemyofibroblast phenotype and release of active tGF-betal from eCM stores. Matrix Biol. (2020) 88:69-88. doi: 10.1016/j.matbio.2019.12.001

61. Hu K, Wu C, Mars WM, Liu Y. Tissue-type plasminogen activator promotes murine myofibroblast activation through $\mathrm{IDL}$ receptor-related protein 1-mediated integrin signaling. J Clin Invest. (2007) 117:382132. doi: 10.1172/JCI32301

62. Ren S, Johnson BG, Kida Y, Ip C, Davidson KC, Lin SL, et al. LRP-6 is a coreceptor for multiple fibrogenic signaling pathways in pericytes and myofibroblasts that are inhibited by dKK-1. Proc Natl Acad Sci USA. (2013) 110:1440-5. doi: 10.1073/pnas.1211179110

63. Avgustinova A, Iravani M, Robertson D, Fearns A, Gao Q, Klingbeil P, et al. Tumour cell-derived wnt7a recruits and activates fibroblasts to promote tumour aggressiveness. Nat Commun. (2016) 7:10305. doi: $10.1038 /$ ncomms10305

64. Ferrari N, Ranftl R, Chicherova I, Slaven ND, Moeendarbary E, Farrugia $\mathrm{AJ}$, et al. Dickkopf-3 links hSF1 and yAP/TAZ signalling to control aggressive behaviours in cancer-associated fibroblasts. Nat Commun. (2019) 10:130. doi: 10.1038/s41467-018-07987-0

65. Derocq D, Prebois C, Beaujouin M, Laurent-Matha V, Pattingre S, Smith GK, et al. Cathepsin $d$ is partly endocytosed by the IRP1 receptor and inhibits IRP1-regulated intramembrane proteolysis. Oncogene. (2012) 31:3202-12. doi: 10.1038/onc.2011.501

66. Choi J, Cha YJ, Koo JS. Adipocyte biology in breast cancer: from silent bystander to active facilitator. Prog Lipid Res. (2018) 69:1120. doi: 10.1016/j.plipres.2017.11.002

67. Masson O, Chavey C, Dray C, Meulle A, Daviaud D, Quilliot D, et al. LRP1 receptor controls adipogenesis and is up-regulated in human and mouse obese adipose tissue. PLoS ONE. (2009) 4:e7422. doi: 10.1371/journal.pone.0007422

68. Jedrychowski MP, Gartner CA, Gygi SP, Zhou L, Herz J, Kandror KV, et al. Proteomic analysis of gLUT4 storage vesicles reveals IRP1 to be an important vesicle component and target of insulin signaling. J Biol Chem. (2010) 285:104-14. doi: 10.1074/jbc.M109.040428

69. Actis Dato V, Chiabrando GA. The role of low-density lipoprotein receptorrelated protein 1 in lipid metabolism, glucose homeostasis and inflammation. Int J Mol Sci. (2018) 19:1780. doi: 10.3390/ijms19061780

70. El Asmar A, El Rassi Z. Hepatoblastoma in childhood, long term survival achieved: 2 case reports and literature review. Int J Surg Case Rep. (2016) 21:55-8. doi: 10.1016/j.ijscr.2016.02.019

71. Zheng XY, Yu BL, Xie YF, Zhao SP, Wu CL. Apolipoprotein a5 regulates intracellular triglyceride metabolism in adipocytes. Mol Med Rep. (2017) 16:6771-9. doi: 10.3892/mmr.2017.7461

72. Pawaria S, Binder RJ. CD91-dependent programming of t-helper cell responses following heat shock protein immunization. Nat Commun. (2011) 2:521. doi: $10.1038 /$ ncomms 1524 
73. Mantuano E, Brifault C, Lam MS, Azmoon P, Gilder AS, Gonias SL. LDL receptor-related protein-1 regulates nFkappaB and microRNA155 in macrophages to control the inflammatory response. Proc Natl Acad Sci USA. (2016) 113:1369-74. doi: 10.1073/pnas.1515 480113

74. Gorovoy M, Gaultier A, Campana WM, Firestein GS, Gonias SL. Inflammatory mediators promote production of shed 1RP1/CD91, which regulates cell signaling and cytokine expression by macrophages. J Leukoc Biol. (2010) 88:769-78. doi: 10.1189/jlb.0410220

75. Staudt ND, Jo M, Hu J, Bristow JM, Pizzo DP, Gaultier A, et al. Myeloid cell receptor IRP1/CD91 regulates monocyte recruitment and angiogenesis in tumors. Cancer Res. (2013) 73:3902-12. doi: 10.1158/0008-5472.CAN-12-4233

76. Njah K, Chakraborty S, Qiu B, Arumugam S, Raju A, Pobbati AV, et al. A role of agrin in maintaining the stability of vascular endothelial growth factor receptor-2 during tumor angiogenesis. Cell Rep. (2019) 28:949-65 e7. doi: 10.1016/j.celrep.2019.06.036

77. Pencheva N, Tran H, Buss C, Huh D, Drobnjak M, Busam K, et al. Convergent multi-miRNA targeting of apoE drives IRP1/LRP8dependent melanoma metastasis and angiogenesis. Cell. (2012) 151:1068-82. doi: 10.1016/j.cell.2012.10.028

78. Li F, Tang SC. Targeting metastatic breast cancer with aNG1005, a novel peptide-paclitaxel conjugate that crosses the blood-brain-barrier (BBB). Genes Dis. (2017) 4:1-3. doi: 10.1016/j.gendis.2017.01.004

79. Lu CW, Lo YH, Chen CH, Lin CY, Tsai CH, Chen PJ, et al. VLDL and IDL, but not hDL, promote breast cancer cell proliferation, metastasis and angiogenesis. Cancer Lett. (2017) 388:130-8. doi: 10.1016/j.canlet.2016.11.033

80. Min JK, Park H, Choi HJ, Kim Y, Pyun BJ, Agrawal V, et al. The wNT antagonist dickkopf2 promotes angiogenesis in rodent and human endothelial cells. J Clin Invest. (2011) 121:1882-93. doi: 10.1172/JCI42556

81. Makarova AM, Lebedeva TV, Nassar T, Higazi AA, Xue J, Carinato $\mathrm{ME}$, et al. Urokinase-type plasminogen activator (uPA) induces pulmonary microvascular endothelial permeability through low density lipoprotein receptor-related protein (LRP)-dependent activation of endothelial nitric-oxide synthase. J Biol Chem. (2011) 286:23044-53. doi: 10.1074/jbc.M110.210195

82. Wang X, Lee SR, Arai K, Lee SR, Tsuji K, Rebeck GW, et al. Lipoprotein receptor-mediated induction of matrix metalloproteinase by tissue plasminogen activator. Nat Med. (2003) 9:1313-7. doi: 10.1038/nm926

83. Mao H, Xie L, Pi X. Low-Density lipoprotein receptor-Related protein-1 signaling in angiogenesis. Front Cardiovasc Med. (2017) 4:34. doi: 10.3389/fcvm.2017.00034

84. Mao H, Lockyer $\mathrm{P}$, Townley-Tilson WH, Xie L, Pi X. LRP1 regulates retinal angiogenesis by inhibiting pARP-1 activity and endothelial cell proliferation. Arterioscler Thromb Vasc Biol. (2016) 36:350-60. doi: 10.1161/ATVBAHA.115.306713

85. Vezina A, Charfi C, Zgheib A, Annabi B. Cerebrovascular angiogenic reprogramming upon IRP1 repression: impact on sphingosine-1-PhosphateMediated signaling in brain endothelial cell chemotactism. Mol Neurobiol. (2018) 55:3551-63. doi: 10.1007/s12035-017-0614-3
86. Zhao Y, Li D, Zhao J, Song J, Zhao Y. The role of the low-density lipoprotein receptor-related protein 1 (LRP-1) in regulating blood-brain barrier integrity. Rev Neurosci. (2016) 27:623-34. doi: 10.1515/revneuro-2015-0069

87. Thomas FC, Taskar K, Rudraraju V, Goda S, Thorsheim HR, Gaasch JA, et al. Uptake of aNG1005, a novel paclitaxel derivative, through the blood-brain barrier into brain and experimental brain metastases of breast cancer. Pharm Res. (2009) 26:2486-94. doi: 10.1007/s11095-009-9964-5

88. Hu G, Chun X, Wang Y, He Q, Gao H. Peptide mediated active targeting and intelligent particle size reduction-mediated enhanced penetrating of fabricated nanoparticles for triple-negative breast cancer treatment. Oncotarget. (2015) 6:41258-74. doi: 10.18632/oncotarget.5692

89. Xue HY, Wong HL. Targeting megalin to enhance delivery of anti-clusterin small-interfering rNA nanomedicine to chemo-treated breast cancer. Eur J Pharm Biopharm. (2012) 81:24-32. doi: 10.1016/j.ejpb.2012.02.005

90. Falciani C, Brunetti J, Lelli B, Ravenni N, Lozzi L, Depau L, et al. Cancer selectivity of tetrabranched neurotensin peptides is generated by simultaneous binding to sulfated glycosaminoglycans and protein receptors. J Med Chem. (2013) 56:5009-18. doi: 10.1021/jm400329p

91. Depau L, Brunetti J, Falciani C, Scali S, Riolo G, Mandarini E, et al. Coupling to a cancer-selective heparan-sulfate-targeted branched peptide can by-pass breast cancer cell resistance to methotrexate. Oncotarget. (2017) 8:76141152. doi: 10.18632/oncotarget.19056

92. Falciani C, Fabbrini M, Pini A, Lozzi L, Lelli B, Pileri S, et al. Synthesis and biological activity of stable branched neurotensin peptides for tumor targeting. Mol Cancer Ther. (2007) 6:24418. doi: 10.1158/1535-7163.MCT-07-0164

93. Falciani C, Brunetti J, Pagliuca C, Menichetti S, Vitellozzi L, Lelli B, et al. Design and in vitro evaluation of branched peptide conjugates: turning nonspecific cytotoxic drugs into tumor-selective agents. ChemMedChem. (2010) 5:567-74. doi: 10.1002/cmdc.200900527

94. Brunetti J, Pillozzi S, Falciani C, Depau L, Tenori E, Scali S, et al. Tumorselective peptide-carrier delivery of paclitaxel increases in vivo activity of the drug. Sci Rep. (2015) 5:17736. doi: 10.1038/srep17736

95. Lu W, Lin C, Roberts MJ, Waud WR, Piazza GA, Li Y. Niclosamide suppresses cancer cell growth by inducing wnt co-receptor IRP6 degradation and inhibiting the wnt/beta-catenin pathway. PLOS ONE. (2011) 6:e29290. doi: 10.1371/journal.pone.0029290

Conflict of Interest: The authors declare that the research was conducted in the absence of any commercial or financial relationships that could be construed as a potential conflict of interest.

Copyright () 2020 Campion, Al Khalifa, Langlois, Thevenard-Devy, Salesse, Savary, Schneider, Etique, Dedieu and Devy. This is an open-access article distributed under the terms of the Creative Commons Attribution License (CC BY). The use, distribution or reproduction in other forums is permitted, provided the original author(s) and the copyright owner(s) are credited and that the original publication in this journal is cited, in accordance with accepted academic practice. No use, distribution or reproduction is permitted which does not comply with these terms. 